\title{
Addressing Adverse Childhood Experiences: It's All about Relationships
}

\author{
Paula Zeanah ${ }^{1, *}$, Karen Burstein ${ }^{2}$ and Jeanne Cartier ${ }^{3}$ \\ 1 College of Nursing and Allied Health, Professions and Picard Center for Child Development, \\ University of Louisiana at Lafayette, Lafayette, LA 70504, USA \\ 2 Research Division, iTether Technologies, Inc. Phoenix, AZ 85016, USA; kburstein@itethertech.com \\ 3 Department of Nursing, College of Nursing and Allied Health Professiions, \\ University of Louisiana at Lafayette, Lafayette, LA 70504, USA; jeanne.cartier@louisiana.edu \\ * Correspondence: paula.zeanah@louisiana.edu
}

Received: 25 September 2018; Accepted: 11 November 2018; Published: 19 November 2018

check for updates

\begin{abstract}
Recognition that economic, environmental, and social adversity affects health is not new; adversity may result from social determinants such as poverty, community violence, or poor nutrition; from within the family/caregiving environment; or interactions between these complex environs. However, compelling new research demonstrating the profound impact of cumulative early adversity and toxic stress on development and adult health is leading to the mobilization of global prevention and intervention efforts to attain and assure better health for populations across the world. In this paper, we begin with a global population perspective on adversity and discuss priorities for global health. We then turn to studies of adverse childhood experiences to consider current understanding of how early experiences impact brain development and short- and long-term health. Factors that build resilience and buffer the effects of toxic stress and adversity are described, with emphasis on the foundationally protective role of safe and nurturing caregiving relationships. We discuss the implications of these findings in terms of community health and present a participatory research paradigm as a relationship-based method to improve community engagement in identifying and mitigating the impact of adverse childhood experiences on health.
\end{abstract}

Keywords: adverse childhood experiences; toxic stress; global health; community-based participatory research

\section{Introduction}

Recognition of how socioeconomic, environmental and psychosocial conditions impact health is generating new avenues for addressing global chronic health conditions, health disparities and inequities, and increasing knowledge of factors associated with positive health. In particular, there is growing attention to how adversity and stress affect short- and long-term health. Research demonstrating the profound impact of early life experiences on the developing brain and later health and development has led to the mobilization of international efforts to develop prevention and intervention efforts to attain and assure better health for populations across the world. In this paper, we use a global population health lens to consider the impact of early adversity on short- and long-term health and development, and discuss how protective factors, especially stable, safe, and nurturing caregiving relationships, can buffer the impact of adversity. We discuss the implications of these findings in terms of community health and highlight the community-based participatory research paradigm as one way to improve community engagement in identifying and addressing social and environmental factors that impact health and mental health. 


\section{Adversity through a Global Population Health Lens}

The global community has a long history of efforts directed toward understanding and acting on the intersections of social determinants and health. The World Health Organization [1] defines the social determinants of health as "the conditions in which people are born, grow, live, work and age" and further assert these factors account for the greatest contribution to health inequalities [2]. The Millennium Development Goals (MDGs) aimed to end global poverty and served as the blueprint for improvement efforts from 2000 to 20015. The MDGs were particularly salient for the lowest income countries, and resulted in significant improvements in childhood mortality, maternal health outcomes, infectious diseases and hunger [1].

The Sustainable Development Goals (SDGs), developed and adopted by the U.N. in 2015, replace and expand upon the MDGs [3]. Incorporating WHO's call for action to address the social determinants of health [4], the SDGs represent a broader range of socioeconomic, health, and environmental issues than those identified in the MDGs. The 17 SDGs and associated targets and indicators are aimed at the entire global community and provide a blueprint for all countries to measure their progress and to assess their standing in the global environment. The global indicator framework, adopted by the General Assembly in 2017, is contained in the Resolution adopted by the U.N. General Assembly on Work of the Statistical Commission pertaining to the 2030 Agenda for Sustainable Development (A/RES/71/313). For a complete listing and discussion of the goals, see https://unstats.un.org/sdgs/. The expanded framework of the SDG's includes two specific populations at an increased risk of poor health outcomes associated with social determinants of health—children exposed to violence and migrants [1].

Global surveys of children exposed to violence, conducted by the U.N. [5], describe both the current state of violence as well as progress over the previous 10-year period. In this U.N. report, violence includes but is not limited to neglect, physical and emotional abuse, and trafficking for prostitution and forced labor. Although improvements were made during the 10-year period of the studies, there are sobering statistics: between 500 million and 1.5 billion children worldwide experience violence on a yearly basis and often during the crucial period of early development. While both males and females are victims of violence, females are disproportionately victimized. Thirty-five percent of women worldwide are estimated to be victims of violence [6], which includes gender-based violence that may cause physical, sexual or psychological harm or suffering to women, threats of harm, coercion, or public or private deprivation of liberty [7].

Violence can be culture-universal or culture-specific. Many culture-specific acts of violence reflect a gender bias towards females, such as rapes, marriage to rapists, forced marriages, honor killings and acid attacks, documented recently by MacKinnon [8] and by the United Nations report on women's rights [9]. Interpersonal violence, suicide, and war and conflict (affecting mostly males) account for $21.7 \%$ of worldwide deaths attributed to injury and violence [1].

High levels of stress and exposure to violence are common experiences for migrants. The unique stressors of migration are associated with all phases of moving from one's country of origin to settling into a host country. Migrants and immigrants often encounter a myriad of difficulties including language difficulties, cultural differences, lack of a political power, as well as injustice and inequality in host countries [10]. A body of evidence supports a relationship between migration, trauma \& Post Traumatic Stress Disorder (PTSD) [11]. Bustamante, Cerqueira, Leclerc, \& Brietzke [11] posit that migrants living under stressful conditions for a sustained period may develop anxiety, depression, and PTSD. Furthermore, the authors note that while exposure to violence associated with war is more likely to occur among refugees, many migrants have experience political threats, interpersonal violence, childhood abuse, and physical assaults. Social and environmental conditions contributing to chronic stress for migrants include poverty and poor living conditions, cultural and linguistic differences that may lead to social isolation and lack of access to health services [11]. 


\section{Adversity through the Lens of Global Hunger and Poverty}

Poverty and associated hunger are additional social determinants of health for people throughout the world. It is difficult at best to work at full productivity, raise a family, study, learn, or develop normally in the continued face of hunger. Today, the United Nations Food and Agriculture Organization (FAO) estimates that about 815 million (10.7\%) of the world's 7.6 billion citizens are suffering from chronic undernourishment. The vast majority of hungry people live in lower-middle-income countries. Africa and southern Asia have the highest prevalence of under-nourishment, however, most countries including the US experience multiple forms of malnourishment, including child overweight, adult obesity, and micronutrient deficiencies, as well as under-nutrition [12,13]. Coincidental with hunger is the increased frequency of food insecurity, defined as the inconsistent access to sufficient, safe, and nutritious foods needed for an active, healthy life [12].

One-third of women of childbearing age worldwide are anemic; and poor nutrition during pregnancy results in undernourishment in-utero, prematurity, and low nutrient stores in infants, leading to low birth weight babies and stunted development [12]. Stunting (impaired growth and development of children, especially in the first three years of life) affects not only physical size but also the cognition and learning of approximately one in four children under five, some 155 million children worldwide [14]. In some regions such as sub-Saharan Africa, 30\% of children have stunted development. The estimated proportions of child deaths in which undernutrition is an underlying cause are similar to that of diarrhea (61\%), malaria (57\%), pneumonia (52\%), and measles $(45 \%)[15,16]$. Undernutrition is also associated with illnesses such as diarrhea that reduce the body's ability to absorb and convert food into nutrients. Given these physical consequences of undernourishment, affected children may be more irritable, have less energy, be less responsive and in general may be more difficult to care for; similarly, it is likely that an undernourished caregiver is less able to respond to the child in a safe, effective, sensitive manner.

Clearly, under- and malnutrition have significant impacts on child health and development, and ensuring optimal maternal nutrition is vital to break this inter-generational cycle. It is important to note that food insecurity is common among immigrants, refugees and asylum seekers, is prominent in households with children [17], and in communities with ongoing community conflict, violence, and civil unrest [18]. Perhaps it is not surprising that the examples of traumas and deprivation presented thus far are related to poor health and developmental outcomes. However, are other types of adversities also associated with poor outcomes? In the next section, we describe the Adverse Childhood Experiences study [19] and related research; these studies are stimulating a volume of research to elucidate and address the impact of early experiences on later health and development. In addition, the findings point to the importance of healthy relationships to ensure the health of populations globally.

\section{What Are Adverse Childhood Experiences (ACEs) and Why Do They Matter?}

The idea that cumulative early adversity affects child developmental outcomes is not new [20,21], but a significant contribution to the understanding of the psychosocial precursors of health is the Adverse Childhood Experiences (ACE) study [19]. A collaborative effort between the Centers for Disease Control and Prevention (CDC-P) and San Diego's Kaiser-Permanente health system, the study included 17,000 members of the Kaiser health system to determine whether adversity experienced prior to age 18 was related to later health outcomes. The retrospective experiences endorsed by participants were synthesized into 10 categories including indicators of household dysfunction (growing up with substance abusing household members, parental separation or divorce, growing up with mentally ill household members or caregivers, witnessing intimate partner violence or criminal behavior as evidenced by having a household member imprisoned); physical, sexual, or emotional abuse; and physical and emotional neglect. Among this generally well-educated middle-class U.S. sample, ACEs were common; approximately two-thirds of the sample experienced at least one ACE, and 16\% 
experienced four or more. In the original study, only $26 \%$ of respondents had no ACEs, and if one ACE was present, there was a high likelihood of the presence of at least one additional ACE [22].

Perhaps most startling of the ACE study findings are the long-term impacts on adult health risk behaviors and outcomes. Consistently, a "dose-response" relationship is found between the number of adverse experiences in childhood and health risk behaviors on adult health outcomes, including but not limited to substance abuse, risky sexual behavior and sexually transmitted infections, depression, suicidal behavior, obesity, heart disease, diabetes, chronic lung disease, and earlier death; ACEs are considered a "hidden burden" on health [19].

Studies of ACEs in populations across the globe show similar findings. A recent study conducted by Bellis et al. [23] examined the experience of ACEs among young adults in eight eastern European countries. Respondents with more than four ACEs, compared to those reporting no ACEs, were significantly more likely to report health-harming behaviors, including physical inactivity, smoking, more than five sexual partners, sexual intercourse before age 16, drug abuse, problematic use of alcohol, and attempted suicide (O.R. range 1.68 for physical activity to 48.53 for suicide attempt).

More recently, Hughes et al. [24] conducted a systematic review and meta-analysis including 37 studies and 253,719 participants. Compared to individuals with no ACEs, those with at least four ACEs had somewhat greater (O.R. <2) likelihood of physical inactivity, overweight, obesity; a moderate likelihood (O.R. 2-3) of smoking, heavy alcohol use, poor self-rated health, cancer, heart disease, and respiratory disease; strong likelihood (O.R. 3-6) for sexual risk taking, mental health issues, problem alcohol use; and the strongest likelihood (O.R. > 7) for problematic drug use and interpersonal and self-directed violence.

Studies also demonstrate the proximal effects of exposure to adversity in young children. Blodgett and Lanigan [25] examined the impact of ACEs on 2100 elementary students in Washington state. Compared to students with no ACEs, those with three or more ACEs were three times more likely to experience academic failure, four times more likely to have poor health, five times more likely to have severe attendance problems, and six times more likely to have school behavior problems. Similarly, Jimenez et al. [26] examined a large urban birth cohort from the Fragile Families and Child Wellbeing Study. Using parent-reported ACEs and teacher reported behaviors in children at age 5, 55\% had experienced one ACE and 12\% had experienced three or more ACEs. Children who experienced three or more ACEs were more likely to have below average language and literacy skills and math skills, poor emergent literacy skills, attention problems, social problems, and aggression.

Another recent study of young children ages 18-71 months who were involved in the child welfare system for suspected or actual abuse found that nearly all (98.1\%) experienced at least one ACE, but the average for these children was 3.6. For each additional ACE reported, there were $21 \%$ increased odds of having a chronic medical condition, 32\% increased odds of having a behavior problem, and a 77\% increased odds of a low socialization score on developmental assessment [27].

A common thread among the ACEs is the reciprocal relationship of the caregiving environment for the child. Obviously, abuse and neglect reflect disrupted and disturbed parent-child relationships. Myriad research documents the adverse effects of parental depression, substance abuse, and parental conflict and interpersonal violence on the ability of parents to provide nurturing, safe, responsive, and dependable caregiving [28,29]. Thus, ACEs are often conceptualized as having a "two-generation" effect [30], in that the experiences of one generation are "passed on" to the next generation through caregiving via behavioral and biological processes (Figure 1). For example, a recent prospective longitudinal study demonstrated biological and psychosocial pathways linking maternal adverse childhood experiences with infant development at age 12 months [31]. However, it is important to note that while ACEs reflect a particular set of adversities, there are many types of adverse experiences that can impact health and development. 


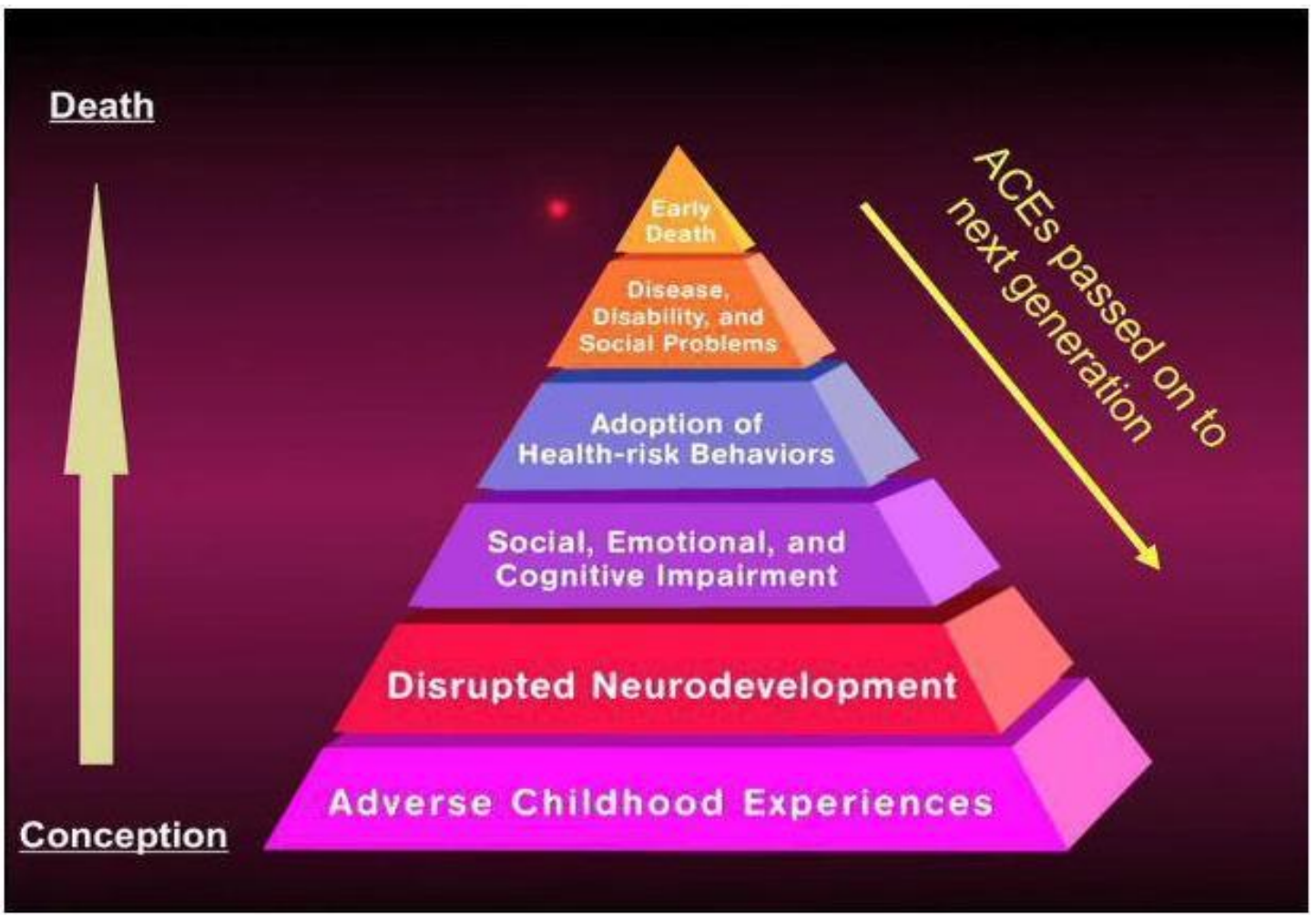

Figure 1. ACE Intergenerational Transmission Pyramid (Source and copyright: ACE Interface Master Trainer program; www.aceinterface.com).

\section{How Does Adversity Affect Short and Long-Term Health?}

Research on the underlying biology of adversity is expanding rapidly, and a detailed description is beyond the scope of this paper. Nevertheless, we briefly describe three different but related pathways currently being explored: early brain development, hormonal effects of stress, and the interaction of genes and experience.

\subsection{Early Brain Development}

While genetics directs the basic wiring of the brain and provides the "expectation" that certain types of experience will occur [32,33], experience shapes the "architecture" of the brain. Within the first few weeks of conception and through the first two trimesters of pregnancy, there is rapid development and differentiation of neural cells. During the last trimester of pregnancy and through the next few years of life, synaptogenesis occurs, creating connections between brain cells, which allows the cells to communicate and coordinate functions [34]. Synaptic connections proliferate most rapidly during the first few years of life, with an estimated 1000/connections per second formed during this period. The creation and sustaining of connections depend on experience [35]. By age 3, a child's brain has more than double the number of synapses he or she will have in adulthood. Through a "pruning" process, the connections that are used more frequently, or are more important or meaningful in terms of survival, remain, and other connections winnow away. Thus, there is a "use it or lose it" phenomenon, demonstrating that quality of input and experience matters $[34,36]$. Neural plasticity, the ability to respond to environmental stimuli, enables humans to more readily adapt to the environment and for the brain to achieve optimal development. Some parts of the brain necessarily develop more rapidly and earlier (e.g., sensory areas develop before the executive functions of the prefrontal cortex), and brain development continues well into early adulthood. However, when the young developing brain experiences chronic threat, stress, or adversity without ways to protect or buffer those effects, 
the mechanisms for the construction of the brain may be impacted with lifelong consequences for development and health [30,34,36].

\subsection{Stress Response System}

Stress includes actual and perceived threats of bodily harm as well as psychological and social threats such as self-esteem, group, and relationship status [37,38]. Stress activates a cascade of autonomic nervous system and neuroendocrine responses, which result in the physiological and behavioral responses to threat $[39,40]$. Much research has focused on the hypothalamic-pituitary-adrenal (HPA) axis and the role of the glucocorticoid hormones (in particular, cortisol) to mobilize metabolic, cardiovascular, immune, and behavioral responses including release of glucose into the blood stream to meet increased energy needs, increased heart rate and blood pressure, and increased cognitive attention/focus, and memory to the environmental factors that are a threat. Stress response is intended to be short lived, with the goal to maintain physiologic homeostasis $[39,40]$. However, because cortisol affects nearly all major organs of the body, prolonged high levels of cortisol have negative impacts on the end-organs [36] and cause dysregulation of the stress response system. These effects are linked to a wide array of pathologies including autoimmune disease, hypertension, affective disorders, and major depression [40].

A number of recent studies explore the relationship between prenatal exposure to high levels of maternal stress and infant and child behavior and physiology. For example, at birth, infants who are exposed to high levels of prenatal stress, evidenced by elevated maternal cortisol levels, show a concomitant higher level of cortisol as well, and such elevations persist into early childhood [38]. Bush et al. [41] also found that prenatal exposure to high levels of maternal stress affected temperamental characteristics and parasympathetic nervous system responses, both associated with early identification of later psychopathology. Similarly, children exposed to high levels of stress in early childhood may show effects well into adolescence [38].

On the other hand, while adverse child health and mental health outcomes are more likely to occur within the context of exposure to high levels of maternal cortisol, such is not always the case [42]. In fact, all stress is not bad. The National Scientific Council on the Developing Child [36] defines three levels of stress. Positive stress results from brief events that result in elevated heart rate and hormone levels, but can result in growth-for example, a separation from caregiver or a brief pain experience. Positive stress is considered a necessary part of healthy development. Tolerable stress results from significant changes or threats, such as a sudden loss of a home or loss of a caregiver. Tolerable stress produces a greater and more prolong physiological reactions, but the effects can be buffered with the presence of a dependable and nurturing caregiver and/or a safe environment. Toxic stress is strong, frequent, and prolonged, and the individual may not have any control over its occurrence. A variety of stresses are associated with toxic stress, including chronic poverty, threats of violence and unsafe living conditions, maltreatment, maternal depression, and exposure to parental interpersonal violence. Exposure to chronically high levels of stress in early childhood is related to a myriad of poor health, developmental, and learning outcomes for children [32,36,43], as well as adult health outcomes independent of age-related risks, the effects of poverty, and over and above non-malleable factors such as family history [44].

\subsection{Gene $x$ Environment Experiences}

Contrary to popular understanding, genes do not necessarily confer static, permanent characteristics. The "structural genome" represents the thousands of genes that individuals inherit from their biological parents. However, the epigenome determines which genes get expressed or not (turned on or off) via chemical modification of genes. Essentially the epigenome is constructed through experience. Quality of nutrition, exposure to toxins, quality of caregiving, and exposure to stress are reflected in and impact genetic regulation and expression [32,45]. Experiences during the prenatal and early infancy period seem to be key in genetic expression in brain and behavioral development. 
Sensitive periods occur when specific genes are particularly susceptible to environmental experiences, for example, during prenatal organ development, or phenome receptivity during the second half of the first year of life. Similarly, gene by environment experiences impact the ability to respond to stress, affecting brain architecture as well as brain chemistry. Additionally, research points to the trans-generational impact of epigenetic influences on genetic expression [46].

Another robust area of research focuses on the association of telomeres and stress. Telomeres are the repetitive DNA sequences at the ends of chromosomes; shortened telomeres, associated with stress, are dose-dependent, and may be predictive of a number of later health conditions including diabetes, cancer, heart disease and early aging $[47,48]$. A recent systematic review found an association with telomere length and early childhood adversity, suggesting telomere length may be a biomarker for later health outcomes [49].

Research on gene by environment interactions provides promising avenues for identification and amelioration of risk. In particular, positive experiences provide a protective or ameliorative effect even at the genetic level.

\section{Mitigating the Short and Long-Term Impacts of Psychosocial Trauma: Resilience and Relationships}

Resilience is the ability to adapt successfully in the face of significant stress, adversity, or trauma [50-52]. There are multiple co-occurring pathways to adaptation, including behavioral, emotional, social, cognitive, and biological, including the neuro-immunological responses of the stress response system and epigenetic responses [52]. Promotive factors are those that enhance positive development whether or not risk factors are present, and protective factors are those which "buffer" the effects of stressful and traumatic experiences [53]. Promotive and protective factors are often the same, and include individual factors, such as good health, strong coping skills, intelligence, and high self-esteem; relationship factors including a safe and dependable caregiving and a secure attachment with the primary caregiver, and reliable mentors; and social and community sources of support, as well as cultural and traditional beliefs and systems $[53,54]$. The presence or absence of these factors before, during, and after traumatic events affect the child's ability to "bounce back" from adversity [53,54]. Similarly, ACE researchers identify three protective systems associated with the prevention and amelioration of ACE: enhancing individual capacities and personal attributes (health, coping, optimism); the presence of safe nurturing attachment relationships and belonging with caring and competent caregivers, and a community that fosters connections, shared responsibility and skills and efficacy $[22,30]$.

The foundationally protective role of safe and nurturing caregiving relationships is well-recognized. Infants who develop a secure attachment with at least one caregiver during the first year of life have better social, cognitive, and emotional development, are less likely to experience behavior and emotional problems, and are better able to cope with adversity $[29,55]$. The parent-infant relationship is the conduit for how the infant experiences environmental influences such as maternal depression, poverty, and interpersonal violence [56]. For example, studies of the impact of maternal depression, an ACE risk factor, on caregiving demonstrate that depressed mothers are less attentive and interactive, less sensitive and responsive to the infant's emotional and behavioral needs. Infants of depressed mothers show more social, emotional and cognitive difficulties which can extend into the school years $[57,58]$. Maternal depression impacts children not just at the behavioral level; infants of depressed mothers also show differences in hormone regulation, brain activation, and genetic regulation $[34,59]$. Furthermore, a growing literature demonstrates how trauma disrupts the behavioral and neurobiological underpinnings of empathy and ability to understand and respond to the emotional experience of self and others $[60,61]$. Research findings on how trauma impacts the ability to understand one's own and others' emotions provide evidence for understanding the intergenerational transmission of the effects of trauma from parent to child, and may point to potential preventive interventions. For example, studies of young children removed from institutional care and 
placed in foster care demonstrate that significant physical, cognitive, social, behavioral and relational improvement can occur when children are placed in safe, responsive, and stimulating caregiving environments [62]. Significantly, young children who were removed from deprivation and placed in foster care before age 24 months also show brain activity similar to non-deprived community children, whereas those placed after 24 months show reductions in brain electrical activity and do not show similar improvements a decade later [63].

These studies contribute to the compelling and rapidly growing volume of research demonstrating the import of early experiences. As a consequence, frameworks that identify risk and protective factors recognize the importance of safe, nurturing caregiving and other relationships for mitigating the impact of adversity on health and development [64-67], and also recognize that parent-infant relationships develop within the contexts of the community and social environments surrounding families [53,67-69]. And, because of the interrelated and compounding effects of stress, adversity, and social, economic, and environmental determinates on immediate and long-term biological, developmental, and health consequences, global health leaders have begun to advocate for "nurturing care", especially during early childhood, to counter the detrimental effects of adversity. Nurturing care includes the range of health, nutrition, safety, responsive caregiving, and inclusive learning provided by parents and within the context of supportive communities [68,70].

\section{The Role of Relationships in Community Resilience}

The individual's experience of ACEs occurs within a community context. Adverse community environments, characterized by poverty, discrimination, violence and high crime rates, community instability, lack of economic opportunities, and lack of basic needs such as housing, transportation, and food sources are generally highly correlated with poor social connections [65]. Furthermore, conditions including poor nutrition, exposure to toxins and infectious diseases, overcrowded living space, and low maternal education are associated with limited availability of resources and all of these adverse community environments can impact the quality of caregiving [68]. Thus, there is interest in identifying protective factors that are characteristic of resilient communities and systems $[52,68]$.

The World Health Organization prioritized building resilient communities and supportive environments to accomplish their population health and well-being goals in Health 2020 [71]. In the U.S., a number of states and communities are developing systems to prevent or ameliorate the impact of ACEs $[65,72,73]$. Strategies include educating community members about ACEs, developing collaborations to connect and align resources, and strengthening research and data capabilities [73]. Importantly, community programs facilitate social support, improve parenting skills and knowledge, further social-emotional development of young children in child care settings, link community services and supports, and respond to early warning signs of trouble and family crises [67]. A specific example of an approach to community resilience is the Building Community Resilience (BCR) model [65]. BCR conceptualizes community resilience as the capacity to support families in daily life, and emphasizes community buffers such as availability of parks and recreation, social support, economic opportunities, and affordable housing. Other characteristics of resilient communities include religious and cultural support systems, community engagement, shared decision-making, laws that protect against violence, discrimination, and abuse, and available health and social systems [54,68].

As community and global efforts expand, engaging and involving communities in research to identify and address specific local challenges and develop protective solutions is urgently needed. Importantly, effective cross-system and cross-disciplinary collaborations require attention to interpersonal, community, and system relationships.

Next, we discuss engagement strategies that have proven effective in enabling establishing relationships and partnerships that enhance communities' abilities to identify resources and approaches to address their unique needs. 


\section{Asset-Based Assessment and Community-Based Participatory Research (CBPR)}

With historical roots in the social reform movements of the late 19th and early 20th centuries [74], CBPR is based on an ecological perspective that encourages close collaboration among citizens, researchers, and professionals to foster constructive community development [75]. Responsive to the limitations of traditional social science research, social psychologist Kurt Lewin [76] sought new methods for understanding and addressing complex human problems through action research. Today, CBPR is defined as a "collaborative research approach that equitably involves, for example, community members, organizational representatives, and researchers in all aspects of the research process. Each partner contributes unique strengths and shared responsibilities to enhance the understanding of a given phenomenon within the social and cultural dynamics of the community, and integrates the knowledge gained with action to improve the health and well-being of community members" ([77], p. 177). CBPR systematically and democratically combines research methods and community capacity-building strategies to bridge the gap between knowledge produced through research, and translation of this research into intervention and policies $[77,78]$. Israel et al. identify CBPR as (i) participatory, (ii) cooperative, as researchers and community members engage in a process in which both contribute equally, (iii) results in co-learning for both groups, (iv) a method for system development and local capacity building, (v) empowering local participants to take control of their lives by building community strength and problem-solving abilities, and (vi) a balance of research and outcomes. Focusing on power with the community partners, empowerment of these partners, and bringing about community change, CBPR is both a research method and an intervention $[79,80]$.

Integral to CBRP are the approaches that emphasize the strengths of local people and their communities, especially their abilities to problem-solve. Frequently, Community Advisory Committees are constituted to assist with capacity-focused assessment as an alternative to needs-based assessment and dissemination of CBPR results to the local community for policy development and sustainability of research results. Developed and honed by McKnight and Kretzmann [81], capacity-building is a key component of rebuilding under-resourced troubled communities. Needs 'maps', when viewed through a deficit lens, portray communities as endless lists of problems and lead to multiple competing priorities and fragmentation of 'band-aid' efforts. Residents begin to view themselves as 'needs' on the map, incapable of taking charge of themselves or lacking the agency to solve their own problems. At best, resources coming from deficit maps support survival but do not potentiate serious change or community development [81]. Furthermore, historic evidence indicates that communities are built from the bottom up and from the inside out, as the help from the outside is limited and typically is funneled to third parties rather than the community. Across the past two decades, community leaders have begun to realize that mapping the community's assets, capabilities, and strengths builds an organic picture of communities' culture, strengths, and innate resources. This alternative capacity-focused path leads toward identification of the capacities, skills, and assets of lower income people and their neighborhoods.

As ACEs disproportionately occur in lower-economic communities [82] in which exist historic mistrust of traditional health care and social service systems, the ability of health and mental health practitioners to identify and address needs using traditional research and evaluation methods are compromised [83]. Given this challenge, CBPR has (re)emerged as an approach that builds the capacities of communities to function as co-investigators, which then yields commitment among all partners and methodologies, and yields results that are more likely to be culturally sensitive and socially valid. For children experiencing ACEs and communities desiring to attenuate ACEs, asset mapping by which community members identify protective factors, skilled professionals, and long-standing assets such as faith-based entities, community-based family supports, and cultural values, CBPR may be a powerful vehicle for understanding the contexts in which adverse experiences occur as well as local resources, strategies, and supports to mitigate their impact [84].

A distinctive CBPR attribute is the active involvement of the people whose lives are affected by the issue under study in every phase of the process [85], and an orientation toward a setting's 
strengths, competencies, and potential promise rather than its weaknesses, deficits and problems [75]. Thus, as recently suggested by Woods-Jaegers and colleagues [86], CBPR can be a feasible approach to examining and addressing the intergenerational cycles of ACE among children in at-risk families. For example, primary goals of ACE-related CBPR may be to: (1) increase families' abilities to comprehend and communicate/share their experiences that result in a common local community-wide description of ACEs; (2) advance knowledge and understanding of ACEs in health, care, and educational settings; and (3) develop simple strategies that link protective factors to at-risk families. The objectives may be to test the effectiveness of strategies designed to help families comprehend the effects of ACE and engage families in active attenuation of ACE; thereby, improving overall health and wellbeing of children at the community level [87].

As indicated, CBPR is closely related to community capacity (CC) network building and collaboration [88], which has been shown to be a powerful component for improving the health and well-being of communities. These networks bring local communities together to restructure natural supports and local resources to meet the needs of families and children, and increase cross-system coordination and flexible funding streams to improve local services and policy. A growing body of research indicates that increased CC may decrease the prevalence of ACE and related behaviors [85].

CBPR, as previously described $[84,85]$, fits well within the community capacity framework. CBPR strategies including asset-based assessment, potentiate capacity building by mobilizing networks to identifying local community members (e.g., formal and informal networks of families, longstanding faith-based organizations, state and local service providers, non-profit organizations, NGOs) to provide not only a baseline of existing supports but also identify areas where more resources may be required. Furthermore, the CBPR process organizes individuals and groups around specific questions. These responses require sharing of experiences and build upon common themes and aspirations. CBPR also builds relationships within communities by recommending collaborative methods for assessing, analyzing, recording and re/constructing community history, traditions, beliefs, rituals, stories, artifacts and other components of cultural identity. Each of these cultural components serve as localized ways of conceptualizing and defining problems, valuing resources as well as identifying immediate and ongoing needs; the elements of which provide community participants with an informed basis for critique, redefinition, and political advocacy. Finally, CBPR can democratize the allocation of resources such as personnel, space, or access to science and technology.

Hall and colleagues [89] report on two Washington state analyses seeking to examine the impact of community capacity building on ACE prevalence. The first study examined changes in scores on a Severity Index across two rating periods, seven years apart. Using a series 15 standardized determinants of health and well-being (similar to ACEs) routinely collected statewide, each community was rated on each index and assigned a summative score at each of the two examination points. Then communities were identified as a funded or unfunded community network. Changes in the Severity Index were examined. Results indicated that funded community networks had lower levels of health and well-being problems across time compared to unfunded community networks, thereby suggesting that funded community networks were more effective at problem solving than unfunded networks.

The second CBPR-influenced Washington study [89] resulted from analysis of bi-annual strategy reports submitted by community networks, which were used to rate the community capacity (CC) of counties by rating each on four dimensions of capacity: focus on inter-related problems, learning, community strategic leadership, and results-based decision making. These ratings, assigned by reliable state employees, yielded 10 high CC and 28 low CC counties; which were then used as a basis by which to compare incidence of ACEs based on the statewide Behavioral Risk Factor Surveillance System (BRFSS) survey results. Noteworthy is that the BRFSS included ACE indices based on the methods of the original Kaiser-CDC ACE Study [19]. Adult ACE prevalence and the impact of age were examined in communities with higher and lower CC. Analyses suggests that prevalence of ACEs, especially in young adults (age 18-34), was lower in communities with a higher CC ratings. 
Additionally, the prevalence of higher (three or more) ACE scores was lower among young adults in these high capacity communities as compared with low capacity communities. Thus, not only does higher CC appear to reduce overall ACE prevalence for young adults overall, CC level appears to specifically reduce the number of young adults with multiple ACEs [89].

More specific examples of ACE focused CBPR include a study designed to inform a community about child abuse. Cardazone, Sy, Chik, and Corlew [88] used a Geographic Information System (GIS) to map resources devoted to child abuse and neglect prevention and compared the resources to areas in Hawaii where there were higher levels of reports of child maltreatment. Their research demonstrated that lower levels of communication between and among public resources correlated with higher levels of abuse. A second study focusing on health disparities in under-represented communities [89] examined the relationship between patient centered outcomes research (PCOR) and CBPR, finding that CBPR is an excellent tool for achieving PCOR goals of improving the health of all people by providing them with evidence-based information so they can make informed healthcare decisions.

\section{Summary and Implications}

As we have noted, the idea that cumulative psychosocial and environmental adversity is bad for child health and development is not new. Nevertheless, compelling research is demonstrating the powerful impact of adverse childhood experiences on adult and population health. Adverse experiences may generate within the family/caregiving environment, as demonstrated by ACE studies, yet these experiences also occur within the community and environmental contexts. In addition, adversity may result directly from environmental, social, and economic conditions such as poverty, poor nutrition, and community violence (the social determinants of health). While family and community risk factors can have additive effects, these risks can be ameliorated through safe, nurturing caregiving relationships and/or supportive community environments. Global efforts such as the SDG's recognize the impact of social determinants of health [3], and new initiatives such as "nurturing care" [68] incorporate research findings to develop innovative approaches to counter the effects of adversity and improve global health through protecting and enhancing early childhood development.

Community-based participatory research strategies hold promise for building the capacity of communities to address salient social and environmental risk factors. CBPR's emphases on strengths building, problem-solving, and developing self-efficacy are similar to approaches espoused by, for example, maternal, infant, and early childhood prevention programs for at-risk families [90]. Interestingly, these often hard-to-reach families are most likely to engage and remain in these services when these services are aligned with the parent/family perceptions of needs, goals, and motives, and services are provided by skilled, compassionate, and trustworthy home visitors [91]. Family engagement is crucial to attaining the desired health and social outcomes of home visiting programs Similarly, CBPR's effectiveness is grounded in engagement of community participants and researchers to identify and prioritize, together, the problems to be solved and solutions that will work. In both examples, establishment of positive relationships are fundamental to achieving desired outcomes.

Interdisciplinary approaches for prevention, intervention and research are needed to better identify needs of individuals and those within communities, including systematic identification of ACEs and environmental risks to stimulate interventions [89]. However, whether one works with parents to support positive relationships with their children, with communities to prevent or address adversity, trauma and stress, or participates in transdisciplinary/cross-sector research of world health goals, each of us must recognize and understand the essential impact of relationships on health and wellness outcomes of children at the biological, interpersonal, and social levels.

Author Contributions: All authors contributed to the conceptualization and draft preparation, review, and editing of this manuscript.

Funding: This research received no external funding. 
Acknowledgments: The authors extend gratitude to Emmanuel Kuada for technical assistance with manuscript preparation.

Conflicts of Interest: The authors declare no conflict of interest.

\section{References}

1. World Health Organization (WHO). Health in 2015: From the MDG's, Millennium Developmental Goals to SDGs, Sustainable Developmental Goals; WHO: Geneva, Switzerland, 2015. Available online: http:/ / apps.who.int/ iris/bitstream/handle/10665/200009/9789241?sequence-1 (accessed on 19 July 2018).

2. World Health Organization (WHO). Commission on Social Determinants of Health. 2008. Available online: http://apps.who.int/iris/bitstream/handle/10665/43943/9789241563703_eng.pdf;jsessionid= C7C01BD2CF8CF0CEB5CC301EDA7D1287? sequence=1 (accessed on 18 July 2018).

3. United Nations (UN). Transforming Our World: The 2030 Agenda for Sustainable Development; UN: New York, NY, USA, 2015. Available online: https:/ / sustainabledevelopment.un.org/post2015/transformingourworld/ publication (accessed on 18 July 2018).

4. World Health Organization (WHO). World Conference on the Social Determinants of Health. 2011. Available online: http:/ / www.who.int/sdhconference/declaration/Rio_political_declaration.pdf (accessed on 17 July 2018).

5. United Nations (UN). Toward a World Free from Violence: Global Survey on Violence against Children; United Nations: New York, NY, USA, 2016. [CrossRef]

6. Amnesty International UK. Violence against Women. Available online: https://www.amnesty.org.uk/ violence-against-women (accessed on 19 August 2018).

7. United Nations (UN). Declaration on the Elimination of Violence against Women 48/104. 1993. Available online: http:/ / www.un-documents.net/a48r104.html (accessed on 19 August 2018).

8. MacKinnon, C.A. Rape, genocide, and women's human rights. In Genocide and Human Rights; Latimer, M., Ed.; Routledge: London, UK, 2017; pp. 133-144, ISBN 9781351157551.

9. United Nations (UN). Women's Rights are Human Rights. 2014. Available online: https://www.ohchr.org/ Documents/Publications/HR-PUB-14-2.pdf (accessed on 19 August 2018).

10. Chetail, V. The human rights of migrants in general international law: From minimum standards to fundamental rights. In Migrants and Rights; Routledge: London, UK, 2017; pp. 3-34.

11. Bustamante, L.H.U.; Cerqueira, R.O.; Leclerc, E.; Brietzke, E. Stress, trauma, and posttraumatic stress disorder in migrants: A comprehensive review. Braz. J. Psychiatry 2018, 40, 220-225. [CrossRef] [PubMed]

12. FAO; IFAD; UNICEF; WFP; WHO. The State of Food Security and Nutrition in the World 2017: Building Resilience for Peace and Food Security; FAO: Rome, Italy, 2017.

13. Bread for the World. 2016 Hunger Report: The Nourishing Effect: Ending Hunger, Improving Health, Reducing Inequality. Bread for the World Institute. Available online: http://hungerreport.org/2016/wp-content/ uploads /2015/11/HR2016-Full-Report-Web.pdf (accessed on 14 July 2018).

14. UNICEF; World Health Organization; The World Bank. Levels and Trends in Child Malnutrition. UNICEF/WHO/World Bank Group Joint Child Malnutrition Estimates Key Findings of the 2018 Edition. Available online: http:/ / data.unicef.org/wp-content/uploads/2018/05/JME-2018-brochure-.pdf (accessed on 24 August 2018).

15. Black, R.E.; Victora, C.G.; Walker, S.P.; Bhutta, Z.A.; Christian, P.; De Onis, M.; Ezzati, M.; Grantham-McGregor, S.; Katz, J.; Martorell, R.; et al. Maternal and child undernutrition and overweight in low income and middle-income countries. Lancet 2013, 382, 427-451. [CrossRef]

16. Bryce, J.; Boschi-Pinto, C.; Shibuya, K.; Black, R.E. WHO estimates the causes of death in children. Lancet 2005, 365, 1147-1152. [CrossRef]

17. Food Research and Action Center. Food Insecurity among Immigrants, Refugees, and Asylees. Children's Health Watch, 2016. Available online: http:/ /org2.salsalabs.com/o/5118/p/salsa/web/common/public/ content?content_item_KEY=13089 (accessed on 14 July 2018).

18. Hendrix, C.; Brinkman, H.-J. Food Insecurity and Conflict Dynamics: Causal Linkages and Complex Feedbacks; Presented at Food Insecurity in Protracted Crises-High Level Expert Forum; Ubiquity Press: Rome, Italy, 2012. Available online: http://www.fao.org/fileadmin/templates/cfs_high_level_forum/documents/FIConflictDynamics-Hendrix_Cullen.pdf (accessed on 10 August 2018). 
19. Felitti, V.J.; Anda, R.F.; Nordenberg, D.; Williamson, D.F.; Spitz, A.M.; Edwards, V.; Marks, J.S. Relationship of childhood abuse and household dysfunction to many of the leading causes of death in adults. The Adverse Childhood Experiences (ACE) Study. Am. J. Prev Med. 1998, 14, 45-258. [CrossRef]

20. Sameroff, A.J.; Seifer, R.; McDonough, S.C. Contextual contributors to the assessment of infant mental health. In Handbook of Infant, Toddler, and Preschool Mental Health; Del Carmen-Wiggins, R., Carter, A., Eds.; Oxford University Press: New York, NY, USA, 2004; pp. 154-196, ISBN 0-19-514438-4.

21. Sanson, A.; Oberklaid, F.; Pedlow, R.; Prior, M. Risk indicators: Assessment of infancy predictors of pre-school behavioural maladjustment. J. Child Psychol. Psychiatry 1991, 32, 609-626. [CrossRef] [PubMed]

22. ACE Interface. ACE Interface Master Trainer Program. Available online: www.aceinterface.com (accessed on 30 July 2018).

23. Bellis, M.A.; Hughes, K.; Leckenby, N.; Jones, L.; Baban, A.; Kachaeva, M.; Povilaitis, R.; Pudule, I.; Qirjako, G.; Ulukol, B.; et al. Adverse childhood experiences and associations with health harming behaviors in young adults: Surveys in eight eastern European countries. Bull. World Health Organ. 2014, 92, 641-655. [CrossRef] [PubMed]

24. Hughes, K.; Bellis, M.A.; Hardcastle, K.A.; Sethi, D.; Butchart, A.; Mikton, C.; Jones, L.; Dunne, M.P. The effect of multiple adverse childhood experiences on health: A systematic review and meta-analysis. Lancet Public Health 2017, 2, e356-e366. [CrossRef]

25. Blodgett, C.; Lanigan, J.D. The association between adverse childhood experience (ACE) and school success in elementary school children. School Psychol. Q. 2018, 33, 137-146. [CrossRef] [PubMed]

26. Jimenez, M.D.; Wade, R.; Lin, Y.; Morrow, L.M.; Reichman, N.E. Adverse experiences in early childhood and kindergarten outcomes. Pediatrics 2016, 137, peds-2015. [CrossRef] [PubMed]

27. Kerker, B.D.; Zhang, J.; Nadeem, E.; Stein, R.E.; Hurlburt, M.S.; Heneghan, A.; Landsverk, J.; McCue Horwitz, S.K. Adverse childhood experiences and mental health, chronic medical conditions, and development in young children. Acad. Pediatric 2015, 15, 510-517. [CrossRef] [PubMed]

28. Harold, G.T.; Sellers, R. Annual research review: Interparental conflict and youth psychopathology: An evidence review and practice update. J. Child Psychol. Psychiatry 2018, 59, 374-402. [CrossRef] [PubMed]

29. National Research Council and Institute of Medicine. Depression in Parents, Parenting and Children: Opportunities to Improve Identification, Treatment, and Prevention; Committee on Depression, Parenting Practices, and the Healthy Development of Children; Board of Children, Youth, and Families; Division of Behavioral and Social Sciences and Education; The National Academies Press: Washington, DC, USA, 2009.

30. Shonkoff, J.P.; Garner, A.S.; American Academy of Pediatrics Committee on Psychosocial Aspects of Child and Family Health; Committee on Early Childhood, Adoption, and Dependent Care; Section on Developmental and Behavioral Pediatrics. The lifelong effects of early childhood adversity and toxic stress. Pediatrics 2012, 129, e232-e246. [PubMed]

31. Racine, N.; Plamodon, A.; Madigan, S.; McDonald, S.; Tough, S. Maternal adverse childhood experiences and infant development. Pediatrics 2018, 141, e20172495. [CrossRef] [PubMed]

32. National Scientific Council on the Developing Child. Early Experiences Can Alter Gene Expression and Affect Long-Term Development: Working Paper No. 10. 2010. Available online: www.developingchild.harvard.edu (accessed on 2 August 2018).

33. Rifkin-Graboi, A.; Borelli, J.L.; Enlon, M.B. Neurobiology of stress in infancy. In Handbook of Infant Mental Health, 3rd ed.; Zeanah, C.H., Ed.; Guilford Press: New York, NY, USA, 2009; pp. 59-79, ISBN 9781462506460.

34. Sheridan, M.; Nelson, C.A. Neurobiology of fetal and infant development. In Handbook of Infant Mental Health, 3rd ed.; Zeanah, C.H., Ed.; Guilford Press: New York, NY, USA, 2009; pp. 40-58, ISBN 9781462506460.

35. National Center on the Developing Child. Five Numbers to Remember About Early Childhood Development (Brief). 2009/2017. Available online: www.developingchild.harvard.edu (accessed on 10 August 2018).

36. National Scientific Council on the Developing Child. Excessive Stress Disrupts the Architecture of the Developing Brain: Working Paper No. 3. 2005/2014. Available online: www.developingchild.harvard.edu (accessed on 10 August 2018).

37. Dickerson, S.S.; Kemeny, M.E. Acute stressors and cortisol responses: A theoretical integration and synthesis of laboratory research. Psychol. Bull. 2004, 130, 355-391. [CrossRef] [PubMed]

38. Koss, K.J.; Gunnar, M.R. Annual Research Review: Early adversity, the hypothalamic-pituitary-adrenocortical axis, and child psychopathology. J. Child Psychol. Psychiatry 2017, 59, 327-346. [CrossRef] [PubMed] 
39. Fink, G. Stress: Concepts, definitions, and history. In Reference Module in Neuroscience and Biobehavioral Psychology; Elsevier: New York, NY, USA, 2017; ISBN 978-0-12-809324-5. [CrossRef]

40. Smith, S.M.; Vale, W.W. The role of the hypothalamic-pituitary-adrenal axis in neuroendocrine responses to stress. Dialogues Clin. Neurosci. 2006, 8, 383-395. [PubMed]

41. Bush, N.R.; Jones-Mason, K.; Coccia, M.; Caron, Z.; Alkon, A.; Thomas, M.; Coleman-Phox, K.; Wadhwa, P.D.; Laraia, B.A.; Adler, N.E.; et al. Effects of pre- and postnatal maternal stress on infant temperament and autonomic nervous system reactivity and regulation in a diverse, low-income population. Dev. Psychopathol. 2017, 5, 1553-1571. [CrossRef] [PubMed]

42. Zijlmans, M.; Riksen-Walraven, J.; Weerth, C. Associations between maternal prenatal cortisol concentrations and child outcomes: A systematic review. Neurosci. Biobehav. Rev. 2015, 53, 1-24. [CrossRef] [PubMed]

43. Luby, J.L.; Barch, D.; Whalen, D.; Belden, A. Association between early life adversity and risk for poor emotional and physical health in adolescence: A putative mechanistic neurodevelopmental pathway. JAMA Pediatric. 2017, 171, 1168-1175. [CrossRef] [PubMed]

44. Danese, A.; Moffitt, T.E.; Harrington, H.; Milne, B.J.; Polanczyk, G.; Pariante, C.M.; Poulton, R.; Caspi, A. Adverse childhood experiences and adult risk factors for age-related disease: Depression, inflammation, and clustering of metabolic risk markers. Arch. Pediatric. Adolesc. Med. 2009, 163, 135-143. [CrossRef] [PubMed]

45. Barker, E.; Walton, E.; Cecil, C. Annual Research Review: DNA methylation as a mediator in the association between risk exposure and child and adolescent psychopathology. J. Child Psychol. Psychiatry 2018, 303-322. [CrossRef] [PubMed]

46. Champagne, F.A. Epigenetic influence of social experiences across the lifespan. Dev. Psychobiol. 2010, 52, 299-311. [CrossRef] [PubMed]

47. Starkweather, A.; Alhaeeri, A.; Montpetit, A.; Brumelle, J.; Filler, K.; Montpetit, M.; Mohanraj, L.; Lyon, D.; Jackson-Cook, C. An integrative review of factors associated with telomere length and implications for biobehavioral research. Nurs. Res. 2014, 73, 36-50. [CrossRef] [PubMed]

48. Price, L.; Kao, H.; Burgers, D.; Carpenter, L.; Tyrka, A. Telomeres and early-life stress: An overview. Biol. Psychiatry 2013, 73, 15-23. [CrossRef] [PubMed]

49. Coimbra, G.; Carvalho, C.; Moretti, P.; Mello, M.; Belangero, S. Stress-related telomere length in children: A systematic review. J. Psychiatr. Res. 2017, 92, 47-54. [CrossRef] [PubMed]

50. Herman, H.; Steward, D.E.; Dias-Granados, N.; Berger, E.L.; Jackson, B.; Yuen, T. What is resilience? Can. J. Psychiatry 2011, 56, 258-265. [CrossRef] [PubMed]

51. Wu, G.; Feder, A.; Cohen, H.; Kim, J.J.; Calderon, S.; Charney, D.S.; Mathe, A.A. Understanding resilience. Front. Behav. Neurosci. 2013. [CrossRef] [PubMed]

52. Matsen, A.; Monn, A. Child and family resilience: A call for integrated science, practice, and professional training. Fam. Relat. 2015, 64, 5-21. [CrossRef]

53. National Child Trauma CTSN Core Curriculum on Childhood Trauma Task Force. The 12 Core Concepts: Concepts for Understanding Traumatic Stress Responses in Children and Families; Core Curriculum on Childhood Trauma; UCLA-Duke University National Center for Child Traumatic Stress: Los Angeles, CA, USA; Durham, NC, USA, 2012.

54. Matsen, A. Global perspectives on resilience in children and youth. Child Dev. 2014, 85, 6-20. [CrossRef]

55. Zeanah, C.H.; Zeanah, P.D. The science of infant mental health. In Handbook of Infant Mental Health, 4th ed.; Zeanah, C.H., Ed.; Guilford Press: New York, NY, USA, 2018.

56. Zeanah, C.H.; Boris, N.W.; Scheeringa, M.S. Psychopathology in infancy. J. Child Psychol. Psychiatry 1997, 38, 81-99. [CrossRef] [PubMed]

57. Alpern, L.; Lyons-Ruth, K. Preschool children at social risk: Chronicity and timing of maternal depressive symptoms and child behavior problems at school and at home. Dev. Psychopathol. 1993, 5, 371-387. [CrossRef]

58. Goodman, S.; Brand, S. Depression and early adverse experiences. In Handbook of Depression, 2nd ed.; Gotlib, I.H., Hammen, C.L., Eds.; Guilford Press: New York, NY, USA, 2009; pp. 249-274, ISBN-13 978-1609181505.

59. Gunnar, M.; Quevedo, K. The neurobiology of stress and development. Ann. Rev. Psychol. 2007, 58, 145-173. [CrossRef] [PubMed]

60. Parlari, M.; Frewens, P.; Nazarov, A.; Oremus, C.; MacQueen, G.; Lanius, L.; McKinnon, M. Alterations in empathic responding among women with posttraumatic stress disorder associated with childhood trauma. Brain Behav. 2014, 4, 381-389. [CrossRef] [PubMed] 
61. Pollak, S.D.; Nelson, C.A.; Schlaak, M.F.; Roeber, B.J.; Wewerka, S.S.; Wiik, K.L.; Frenn, K.A.; Loman, M.M.; Gunnar, M.R. Neurodevelopmental effects of early deprivation in post-institutionalized children. Child Dev. 2010, 81, 224-236. [CrossRef] [PubMed]

62. Zeanah, C.H.; Humphreys, K.L.; Fox, N.A.; Nelson, C.A. Alternatives for abandoned children: Lessons from the Bucharest Early Intervention Project. Curr. Opin. Psychol. 2017, 15, 182-188. [CrossRef] [PubMed]

63. Vanderwert, R.; Fox, N.A.; Nelson, C.A.; Zeanah, C.H. Normalization of EEG activity among previously institutionalized children placed into foster care: A 12-year follow-up of the Bucharest Early Intervention Project. Dev. Cognit. Neurosci. 2016, 17, 68-75. [CrossRef] [PubMed]

64. Centers for Disease Control and Prevention. Essentials for Childhood: Steps to Create Safe, Stable, and Nurturing Relationships and Environments for All Children. Available online: http:/ www.cdc. gov/ViolencePrevention/childmaltreatment/essentials/index.html (accessed on 15 July 2018).

65. Ellis, W.R.; Dietz, W.S. A new framework for addressing Adverse Childhood Experience: The Building Community Resilience model. Acad. Pediatr. 2017, 17, S86-S93. [CrossRef] [PubMed]

66. Traub, F.; Boynton-Jarrett, R. Modifiable resilience factors to childhood adversity for clinical pediatric practice. Pediatrics 2017, 139, e20162569. [CrossRef] [PubMed]

67. Center for the Study of Social Policy. Core Meanings of the Strengthening Families Protective Factors; Center of the Study for Social Policy: Washington, DC, USA, 2015. Available online: https:/ / cssp.org/resource/coremeanings-of-the-strengthening-families-protective-factors / (accessed on 18 July 2018).

68. Lancet. Series Advancing Early Child Development: From Science to Scale. 2016. Available online: Thelancet.com/series/ecd/2016 (accessed on 4 August 2018).

69. Verbitsky-Savitz, N.; Hargreaves, M.; Penoyer, S.; Morales, N.; Coffee-Borden, B.; Whitesell, E. Preventing and Mitigating the Effects of ACEs by Building Community Capacity and Resilience: APPI Cross-Site Evaluation Findings; Mathematica Policy Research: Washington, DC, USA, 2016. Available online: http:/ /www.appi-wa.org/ (accessed on 28 July 2018).

70. Richter, L.M. Supporting parents to provide nurturing care to young children. Zero To Three 2018, 38, 10-16.

71. World Health Organization (WHO). Building Resilience: A Key Pillar of Health 2020 and Sustainable Development Goals-Examples from the WHO Small Countries Initiative; Regional Office of the World Health Organization: Copenhagen, Denmark, 2017. Available online: http://www.euro.who.int/en/publications/abstracts/ building-resilience-a-key-pillar-of-health-2020-and-the-sustainable-development-goals-examples-fromthe-who-small-countries-initiative-2017 (accessed on 30 July 2018).

72. Forstadt, L.; Cooper, S.; Andrews, S. Changing medicine and building community: Maine's Adverse Childhood Experiences Momentum. Perm. J. 2015, 19, 92-95. [CrossRef] [PubMed]

73. Larkin, H.; Shields, J.J.; Anda, R.F. The health and social consequences of Adverse Childhood Experiences (ACE) across the lifespan: An introduction to prevention and intervention in the community. J. Prev. Interv. Community 2012, 40, 263-270. [CrossRef] [PubMed]

74. Addams, J. Twenty Years at Hull House; University of Illinois Press: Chicago, IL, USA, 1910/1990.

75. Weissberg, P.; Greenberg, M.T. Prevention science and collaborative community action research: Combining the best from both perspectives. J. Mental Health 1998, 7, 479-492.

76. Lewin, K. Action research and minority problems. J. Soc. Issues 1946, 2, 34-46. [CrossRef]

77. Israel, B.A.; Schulz, A.J.; Parker, E.A.; Becker, A.B. Review of community-based research: Assessing partnership approaches to improve public health. Annu. Rev. Public Health 1998, 19, 173-202. [CrossRef] [PubMed]

78. Mittelmark, M.B.; Hunt, M.K.; Heath, G.W.; Schmid, T.L. Realistic outcomes: Lessons from community-based research and demonstration programs for the prevention of cardiovascular diseases. J. Public Health Policy 1993, 14, 437-462. [CrossRef] [PubMed]

79. Branom, C. Community-based participatory research as a social work research and intervention approach. J. Community Pract. 2012, 20, 260-273. [CrossRef]

80. Reid, S.D.; Reddock, R.; Nickenig, T. Breaking the silence of child sexual abuse in the Caribbean: A community-based action research intervention model. J. Child Sexual Abuse 2014, 23, 256-277. [CrossRef] [PubMed]

81. McKnight, J.L.; Kretzmann, J. Mapping Community Capacity; Institute for Policy Research, Northwestern University: Evanston, IL, USA, 1996. 
82. Ekono, M.; Yang, J.; Smith, S. Young Children in Deep Poverty; National Center for Children in Poverty, Mailman School of Public Health, Columbia University: New York, NY, USA, 2016.

83. Corbie-Smith, G.; Thomas, S.B.; Williams, M.V.; Moody-Ayers, S. Attitudes and beliefs of African Americans toward participation in medical research. J. Gen. Int. Med. 1999, 14, 537-546. [CrossRef]

84. Belle-Isle, L.; Benoit, C.; Pauly, B. Addressing health inequities through social inclusion: The role of community organizations. Action Res. 2014, 12, 177-193. [CrossRef]

85. Minkler, M. Using participatory action research to build healthy communities. Public Health Rep. 2000, 115, 191. [CrossRef] [PubMed]

86. Woods-Jaeger, B.A.; Cho, B.; Sexton, C.C.; Slagel, L.; Goggin, K. Promoting resilience: Breaking the intergenerational cycle of adverse childhood experiences. Health Educ. Behav. 2018. [CrossRef] [PubMed]

87. Burstein, K.; Bryan, T.; Chao, P.-C. Promoting self-determination skills among youth with special needs using participatory action research. J. Dev. Phys. Disabil. 2005, 17, 185-201. [CrossRef]

88. Cardazone, G.; Sy, A.U.; Chik, I.; Corlew, L.K. Mapping one strong ‘Ohana: Using network analysis and GIS to enhance the effectiveness of a statewide coalition to prevent child abuse and neglect. Am. J. Community Psychol. 2014, 53, 346-356. [CrossRef] [PubMed]

89. Hall, J.; Porter, L.; Longhi, D.; Becker-Green, J.; Dreyfus, S. Reducing adverse childhood experiences (ACE) by building community capacity: A summary of Washington Family Policy Council research findings. J. Prev. Interv. Community 2012, 40, 325-334. [CrossRef] [PubMed]

90. Sofolahan-Oladeinde, Y.; Mullins, C.D.; Baquet, C.R. Using community-based participatory research in patient-centered outcomes research to address health disparities in under-represented communities. J. Comp. Eff. Res. 2015, 4, 515-523. [CrossRef] [PubMed]

91. Maternal Infant, and Early Childhood Home Visiting Technical Assistance Coordinating Center. MIECHV Issue Brief on Family Enrollment and Engagement. 2015. Available online: https:/ / mchb.hrsa.gov/sites/default/files/mchb /MaternalChildHealthInitiatives /HomeVisiting/ tafiles/enrollmentandengagement.pdf (accessed on 24 July 2018).

(C) 2018 by the authors. Licensee MDPI, Basel, Switzerland. This article is an open access article distributed under the terms and conditions of the Creative Commons Attribution (CC BY) license (http:/ / creativecommons.org/licenses/by/4.0/). 